\title{
Mechanical Characteristic and Water absorption Property of Bio Composite from Sago Starch and Jute Fiber (Boehmeria Nivea) as The Filler
}

\author{
Rozanna Dewi*, Oktaviani, Zainuddin Ginting, Novi Sylvia, Cindia Ramadhan \\ Department of Chemical Engineering, Universitas Malikussaleh, Aceh, Indonesia. \\ *Corresponding author E-mail: rozanna.dewi@unimal.ac.id
}

Manuscript received 16 Nov 2021; revised 20 Nov 2021; accepted 1 Jan 2022. Date of publication 10 Jan 2022

\begin{abstract}
Eco-friendly plastic can be degraded biologically in an anaerobic environment. This plastic synthesize from starch such as sago starch that is available abundantly at the moment. In the form of bio plastic, the mechanical property still cannot be compared with conventional plastic derived from crude oil, hence the application become limited. Incorporating filler will improve its mechanical property, one of the chosen filler is jute fiber as used in this research. Jute fiber is a natural fiber. Thermoplastic starch (TPS) from sago with jute fiber as a filler and addition of Polypropylene to improve the mechanical properties with certain composition to maintain its biodegradability naturally. The mechanical properties analyzed were tensile strength test, elongation and modulus of elasticity. Water absorption test was conducted as well to observe the water resistance property. The results of tensile strength test showed the best tensile strength values of 9.32 Mpa obtained at the fiber addition of 35\% with a Ratio TPS : PP of 1:1.5. The same condition obtained for percent elongation with the result of $10.16 \%$ and modulus of elasticity of $91.73 \mathrm{Mpa}$. Water absorption showed $55 \%$ filler gave the lowest water absorption, $4.41 \%$ at ratio of TPS : PP 1:0.5. Addition of fiber filler into the bio composite has influenced the tensile strength, elongation and modulus elasticity, higher filler volume incorporating into the bio composite has lowering the tensile strength, elongation and modulus elasticity value, or vice versa. Ratio polypropylene matrix added has influenced as well, the higher ratio has contributed to the higher tensile strength, elongation and modulus elasticity. Addition of polypropylene has limited the ability of bio composite to absorb water. High water absorbency will reduce the performance of bio composite, so the lower the ability of the water absorption, the better the quality of bio composite product and the broader the application can be.
\end{abstract}

Keywords: Bio Composite, Jute Filler, Tensile Strength, Modulus Elasticity, Water Absorbency/

\section{Introduction}

Concerns have been raised about the need to replace of petroleum-based polymers due to the shortage of fossil resources and their impact on the environmental. Recently, several researchers studied the potential of natural, renewable resources including starch, chitosan, chitin, and pectin have been extensively studied as a replacement for non-degradable petroleum derivatives. Among all agricultural resources, cellulose is cheaper than starch. Starch is the most abundant food commodity. There were numerous studies on bioplastics or bio composites based on starch, as it contains more than two hydroxyl groups per anhydrous glucose repeating unit, so that in combination with either a polyol or a cross-linking agent, it can be used for the preparation of polyurethane foams. Bioplastic widely used in home appliances and industrial sector due to its advantage such strong material, resistant to corrosion, more economical, biodegradable in shorter period of time compared to conventional plastic [1] [2].

The potential of sago (Metroxylon Sago) as a source of food and industrial materials has been recognized since the 1970s, but until now the development of the plant sago palm in Indonesia is still in place. Sago is a plant native to Indonesia. Sago starch contains amylose $27 \%$ and amylopectin $73 \%$. Deposits of carbohydrates in the forest of sago Indonesia reached 5 million tons of dry starch per year. Compared with plants producing other carbohydrates, the main advantages of sago plant is a high productivity. The production of well managed sago can reach 25 tons of dry starch/ha/year. Productivity is equivalent to the cane, but higher than cassava and potatoes with the productivity of dry starch 10-15 t/ha/year. Consumption of sago starch in a country only about 210 tons or just $4-5 \%$ of the potential production [3].

Bio-based composites can be generated by preparing a matrix of carbohydrates or proteins, which are extracted either from plant or animal sources. One of the most attractive bio composite materials is by utilizing starch due to its high availability, inexpensive, and renewable material to produce bio-based polymer such as bio-plastic. Other natural sources can be used as matrices such as the protein of sunflower, Amaranth flour, Pea starch, rice flour and polybutylene adipate co-terephthalate, corn flour and chitosan [4]. 
Bio composites consist of biodegradable polymers as the matrix material and biodegradable fillers, usually bio fibers (e.g. lignocellulose fibers). Since both components are biodegradable, the composite as the integral part is also expected to be biodegradable. Cellulosebased fibers are the most widely used, as biodegradable filler. Intrinsically, these fibers have a number of interesting mechanical and physical properties. With their environmentally friendly character and some technoeconomical advantages, these fibers are of interest in an increasing number of industrial sectors (e.g. automotive) to replace glass fibers [3].

Polypropilene is a hydrocarbon polymer and included as thermoplastic polymer which can be processed at high temperature. This type of plastic is usually transparent but not clear or cloudy, hard but flexible, strong, the surface is waxy, resistant to chemicals, heat and oil, softened at a temperature of $140{ }^{\circ} \mathrm{C}[5]$ [6].

In this research, the plasticized thermoplastic starch wants to be modified with jute fiber (Boehmeria Nivea) a cellulose-based fillers, to become environmentally friendly composites. Addition of polypropylene is used to improve composite strength and give plastic behaviour as the thermoplastic sago starch has limited strength if used as single matrix without additional synthetic polymer. The variation of the jute fiber used is $35,40,45,50$ and $55 \%$. This environmentally friendly composite is expected to have better chemical, physical, mechanical, thermal and water absorption characteristics than thermoplastic starch alone. Eco-friendly composites are expected to be a solution to reduce plastic waste because they can decompose naturally in a relatively short time [7].

\section{Literature Review}

Several research have been done in this area. Sudi et al, 2013 conducted a research developing a polymer with adding durian seed starch as a filler into the synthetic polymer used for the manufacture of packaging materials and food containers such as polystyrene (PS) [8]. Punyamurthy et all, 2005 studied the fabrication and characterization of untreated and benzenediazonium chloride treated (Diazo treated) abaca polypropylene composites. A set of composites were prepared along with coupling agents and the other set devoid of coupling agents [9] [10]. The chemical and morphology of nanofibers isolated from rice straw by applying a high shear homogenization technique and its influence on mechanical properties of starch composite foam using thermal compression molding technique was done by Srithongkham et all, 2012. [11] [12]. Silviana and Subagio, 2019 utilize cassava bagasse as a matrix of composite reinforced by acetylated micro fibrillated cellulose (MFC) of bamboo, plasticized by EWCO, and crosslinked with lime with further characterization of the bio composite. Characterization of the product have been carried out in several kinds of analysis, i.e. mechanical by tensile strength, thermal stability by DSC-TGA analysis, qualitative functional group structural by FTIR analysis, and crystallinity by XRD analysis [4] [13].

\subsection{Thermoplastic Sago Starch}

Starch as biodegradable polymer to replace synthetic polymer has still needed to improve because of complex disadvantages including brittleness in the absence of suitable plasticizers, hydrophilic nature of starch and poor water resistance, deterioration of mechanical properties upon exposure to environmental conditions like humidity, and soft and weak nature of starch in the presence of plasticizers. Starch as an inexpensive material and renewable source is biodegradable and biocompatible. Its small granule size makes it as good particulate filler in many polymer blending systems. Also starch has its stiffness, tensile strength, and gas permeability are comparable to those of synthetic polymers from fossil fuels as a matrix in composite

The concentration of starch to water will affect the viscosity of the solution forming a layer of plastic and the thickness of the film formed. The more viscous the starch solution the thick film layer is formed. The thicker the layer is formed to produce more clusters of hydrophilic which is very easy to interact with water. In its application in biodegradable plastic, starch is mixed with the grain of its natural that kept whole, or melted and mixed in a level of molecules with the polymer as appropriate.

Granules of starch can be included as biodegradable fillers in polymer synthetic non-biodegradable. In principle, the starch according to the process as thermoplastic. The nature of the starch does not dissolve in water but if the suspension of starch is heated will happen gelatinization after reaching a certain temperature (the temperature of gelatinization). This is caused by the heating of the kinetic energy of the water molecules become more powerful than the power of attraction between the molecules of starch in the granules, so that the water can get into the starch and the starch will swell. Granule starch can swell and burst and so can not be return in its original condition. Change the properties is called gelatinization. To further increase the economic value of the stem of the sago, sago starch can be used as raw material for the manufacture of biodegradable plastic.

Used polyurethane pre polymer that are synthesized from isocyanates and polyols to strengthen starch thermoplastics. This research produced modified thermoplastic starch that was cross-linked with polyurethane pre polymer obtained from Diphenyl methane di isocyanate and castor oil polyol which had better mechanical, thermal and chemical characteristics than bioplastics and could biodegrade naturally [14]. Subsequent research was carried out by adding chitosan as a reinforcement as well as antibacterial which can improve the mechanical performance of the resulting thermoplastic [15].

\subsection{Bio composite}

Bio composite or composite green is defined as a composite material composed of bio fiber or natural fibers that can be degraded and the polymer can be degraded (non-biodegradable) or that can be degraded (biodegradable) as a matrix function. The development of research bio composite has been very diverse, not only includes products for the needs of building materials, such as particle board, plywood or cement board and other, but has also grown by leaps and bounds in science and bio-plastic or plastic reinforced with cellulose materials, either in the form of products of wood plastic composite (wpc) or injection molded natural fiber polymer. Plastic products plays an important role in the development of the automotive industry that are environmentally friendly [16].

Bio-based composites can be generated by preparing a matrix of carbohydrates or proteins, which are extracted either from plant or animal sources. One of the most attractive bio composite materials is by utilizing starch due to its high availability, inexpensive, and renewable material to produce bio-based polymer such as bio-plastic. Other natural sources can be used as matrices such as the protein of sunflower, Amaranth flour, Pea starch, rice flour and polybutylene adipate co-terephthalate5, corn flour and chitosan [17].

They are widely used for different applications as Automotive Industry, Aerospace Industry, Building Industry, Furniture Industry, Bio medical Industry etc. The need for lightweight, dimensionally stable materials for automotive and aerospace applications opened new frontiers of advanced materials. Natural fiber composites are being used for manufacturing many components in the automotive sector. Typical market specification natural fiber composites include elongation and ultimate breaking force, flexural properties, impact strength, acoustic absorption, suitability for processing and crash behavior. Plant fibers are mainly used in the part of car interior and truck cabins. The use of plant fiber based automotive parts such as various panels, shelves, trim parts and brake shoes are attractive for automotive industries worldwide because of its reduction in weight about $10 \%$, energy production of $80 \%$ and cost reduction of 5\% [18]. 


\subsection{Matrix and Jute Fiber}

To improve the performance such as moisture resistibility, mechanical properties, and long-term stability, several starch-based multiphase systems have been developed during the last two decades, such as blends or composites. Starch is often blended with other polymers (mainly biodegradable) such as poly(lactic acid) (PLA), polycaprolactone (PCL), poly(butylene succinate adipate) (PBSA), poly(butylene adipate-co-terephthalate) (PBAT), poly(vinyl alcohol) (PVA), and many more [19].

The matrix is a phase in the composites have a part or fraction of the volume of the largest (dominant). The matrix has a function to transfer the voltage to the fiber evenly, protect the fibers from mechanical friction, hold and maintain the fiber in place, protecting it from adverse environmental, remain stable after the manufacturing process.

Jute is produced from plants of the genus Corchorus, which includes about 100 species. It is one of the cheapest natural fibres and is currently the best fibre with the highest production volume. Bangladesh, India and China provide the best condition for the growth of jute [20]. It is known by the name of Boehmeria Nivea. In West Java is called by the name of haramay and gambe in Sulawesi. In the international trade of plants is known as ramie. Natural fiber jute has the opportunity to be developed as a medium of reinforcement in a polymer resin. All natural fibers from plants have properties hydrophilic which is very contrary to the nature of the hydrophobic polymer. In this study, alkali treatment such as the use of $\mathrm{NaOH}$ is intended to reduce the hydrophilic natural fiber that is expected to have compatibility with the hydrophobic polymer.

\section{Methods}

\subsection{Working Procedure}

Materials and equipment required in this study, among others, is sago flour, jute fiber, distilled water, polypropilene, glycerol, Methylene Diphenyl Diisocyanate (MDI), polyol, and 5\% $\mathrm{NaOH}$, beaker glass, analytical balance, hot plate, measuring cup, spatula, thermometer, oven, knife, casting glass, pot, torsee's electronic system, spectrophotometry. Fixed variable are as follow 50 grams of sago flour, 9 grams MDI, 12 grams of polyol and 5 grams of glycerol. The independent variable is the volume of the fiber jute $35 \%, 40 \%, 45 \%, 50 \%$, $55 \%$, and the ratio of TPS:PP is $1: 0,5 ; 1: 1 ; 1: 1,5$.

This research method included the stages of preparation of polymer fiber, producing starch thermoplastic and bio composite and stage of analysis. The analysis done was to measure mechanical property (tensile and elongation) of bio composite to understand its strength, biodegradability and functional group structural.

At the preparation of polymer fibers, jute fibers are washed and small cut and smoothed using a blender, sifted using 50 mesh 50 , then soaked with $5 \% \mathrm{NaOH}$ for 2 hours after it is neutralized and dried. The second stage of the preparation of thermoplastic that is weighed jute fiber, 5000 grams sago flour $200 \mathrm{ml}$ water, jute fibers with water and then mixed after it is heated and stirred until it becomes a gel at a temperature of gelatinization $70^{\circ} \mathrm{C}$ for 25 minutes. The mixture was cooled and then added the 9 grams MDI, 12 grams polyol and 5 grams glycerol. The mixture homogeny dried using an oven at a temperature of $80^{\circ} \mathrm{C}$ for 24 hours, then the mixture is dried to be shaped like crust, then blended into a smaller size. The third stage of the preparation of bio composite was heating polypropylene in a frying pan until melted, added 50 grams starch thermoplastic, stirring until homogeny and then printed in casting glass and pressed for 25 minutes.

\subsection{Analysis}

The mechanical test is tensile test and elongation at break. Tensile strength test and elongation at break were performed by Electronic System Universal Testing Machines (ASTM D882-81). Another test performed was water resistant to observe the ability of bio composite to absorb water.

\section{Results and Discussion}

Mechanical test was done using Tensile and elongation test. The tensile strength of a material is the tensile strength of the test material to accept the load without being damaged or broken. The value of tensile strength does not depend on the size of the material but because on the type of material. Other factors contribute to the strength such as the presence of impurities in the material, temperature and humidity of the test environment, and the preparation of specimens. Elongation is a change in maximum length before the bio composite is cut off. Elongation percentage presented the ability of bio composite to stretch to the maximum.

\subsection{Tensile Strength}

Mechanical testing was performed in accordance with standard ASTM D 638-03 using the Torsee's Electronic System test machine. The measurement reults are carried out to determine the tensile strength and elongation. The effect of filler concentration on bio composite tensile strength can be seen in Figure 1.

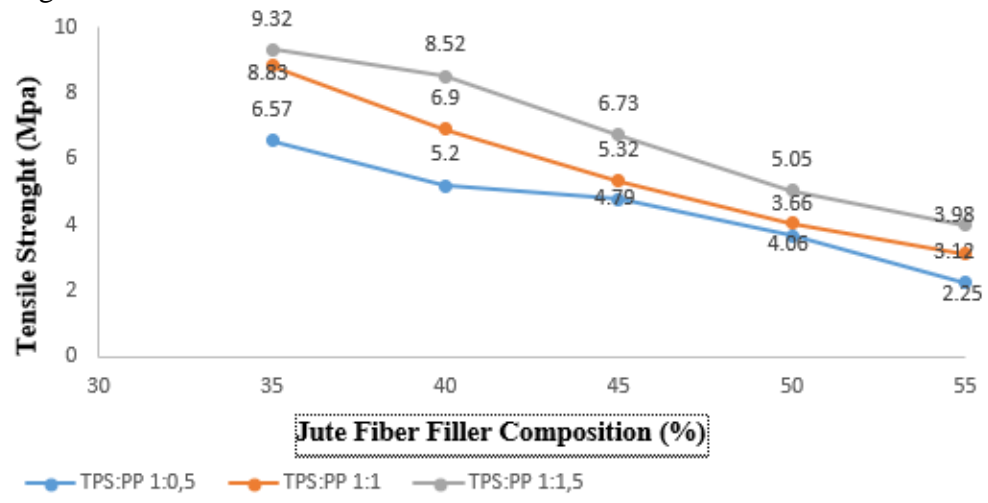

Fig 1. Relation between Tensile Strength of Bio composite with Jute Fiber Filler on different ratio of propylene composition 
From Figure 1 shows that the value of tensile strength is influenced by the composition of the raw material of the composite. The highest tensile strength values $9.32 \mathrm{Mpa}$ obtained at the ratio of TPS : PP of 1:1.5 with the addition of $35 \%$ filler jute fiber. While the addition of $55 \%$ filler jute fiber resulted in a decrease in tensile strength to $3.98 \mathrm{Mpa}$. More filler added into the bio composite has led into the decreasing the tensile strength. The decrease of tensile strength in the sample caused by the interaction between the matrix and filler is weakened, so that the force exerted on the matrix does not transfers well on filler which finally make the composite to be less robust against load. Polypropylene is used to improve composite strength and give plastic behaviour as the thermoplastic sago starch has limited strength if used as single matrix without additional synthetic polymer. However, addition polypropylene into the mixture will influence the biodegradability rate, hence it is required to look carefully at the amount of PP add into the mixture. Biodegradability of this composite will be discuss somewhere else.

This is in accordance with research conducted by Ningsing et all, 2012, added banana starch into the matrix polypropylene (PP) and get the value of the tensile strength of the optimum on the addition of the starch 2 grams, but on the addition of starch 3 grams the value of the tensile strength decreased [12]. Other study had also been carried out by Sudi, 2013, mechanical properties on composite matrix polystyrene material added with durian seed starch and obtain tensile strength values decreased on the addition of starch is above 5\% [9].

The decrease in tensile strength can also influence by sago matrix (TPS), because with the decreasing weight of the sago matrix (TPS), the matrix is not able to bind the filler well. As a result, when the load is applied, the load is not maximally distributed due to the weak bond between the filler and the matrix. Another factors that can affect a decrease in the strength of the composite was uneven mixture of the matrix and the filler used and the presence of voids (holes). In addition, it is also influenced by the position of the filler which is not related to each other which causes the bio composite to break easily in the matrix. Less filler used will reveal greater tensile strength, whereas too much filler used will not provide a balance with the weight of the matrix, then the tensile strength of the bio composite will be lower.

\subsection{Percent Elongation}

Elongation percentage is the length increase of a test material due to the withdrawal load until just before experiencing fracture. The relationship of jute fibre filler composition on elongation percentage can be seen in Figure. 3 below.

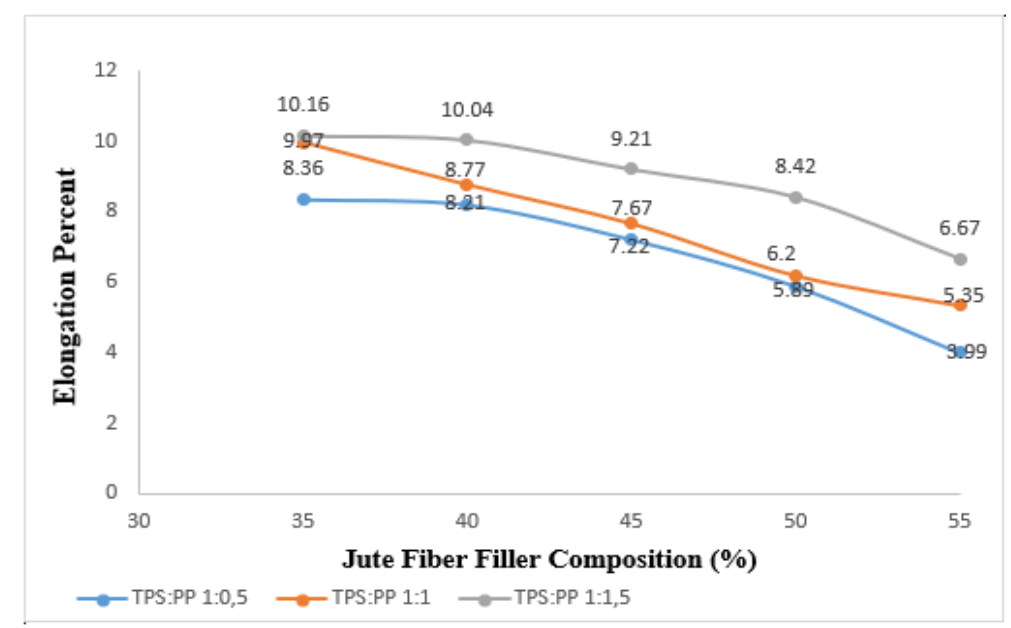

Fig 2. Relation between percent elongations of Bio composite with Jute Fiber Filler on different ratio of propylene composition

In Figure 2, the results of the percent elongation test has indicated the highest elongation value of $10.16 \%$ obtained at the incorporation of $35 \%$ jute fiber at the ratio of TPS:PP of 1:1.5. Meanwhile, the lowest elongation value of $3.99 \%$ occurred at addition of $55 \%$ jute fiber and the ratio of TPS:PP 1:0,5. The elongation decreased due to the increase in the weight fraction of the filler which was too much. This reduction in elongation is due to the increase in the number of fibre in the filler in the bio composite which will further prevent the polypropylene polymer from moving from one place to another so that it will result in early failure when it is loaded. The more polypropylene added to composite will reduce the percent elongation as well. Percent elongation should be designed according to the needs and application, hence it should become the consideration when characterize the quality of the bio composite whether the products is desire to be flexible or less flexible.

\subsection{Modulus of Elasticity with different filler composition}

Value of Modulus of elasticity of the composite is the ratio between the voltage with a strain that occurs, or can be said as the level of stiffness of a material. Modulus elasticity is shown in Figure 3. 


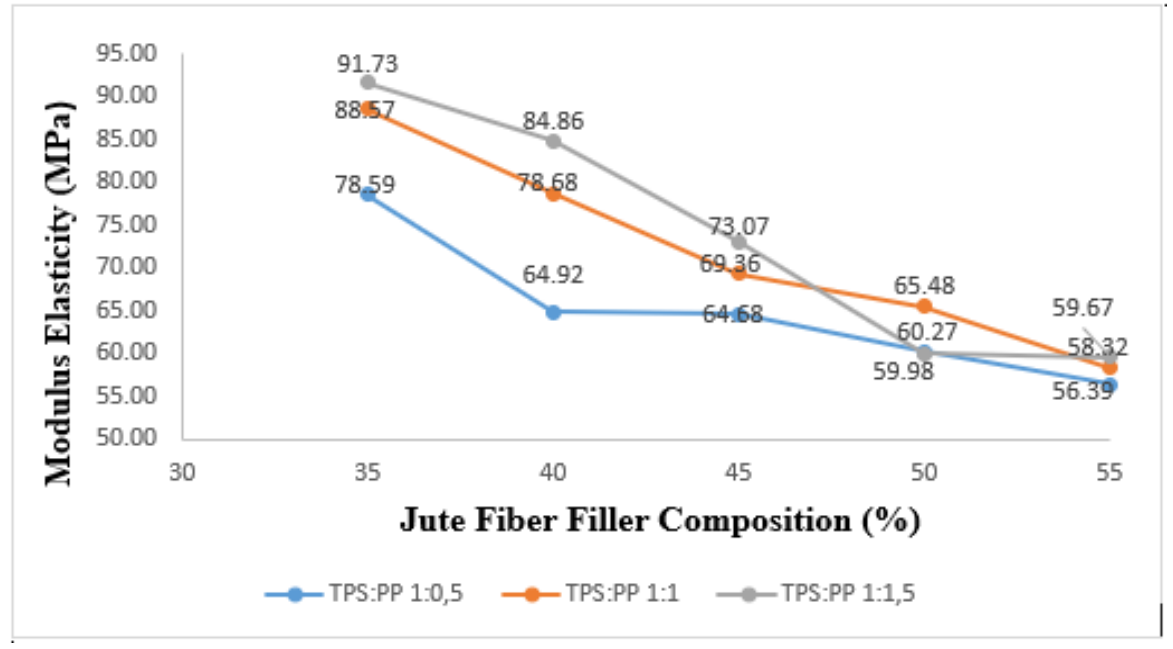

Fig 3. Modulus of Elasticity of Bio Composite with different Composition of Jute Fiber Filler on different ratio of propylene composition

From Figure 3, it can be seen the highest modulus elasticity of $91.73 \mathrm{Mpa}$ and obtained at the filler concentration of 35\%. The lowest modulus elasticity was obtained at the highest concentration of filler of 55\% with modulus elasticity of $59.67 \mathrm{Mpa}$. Addition of fiber filler into the bio composite has influenced the modulus elasticity, higher filler volume incorporating into the bio composite has lowering the modulus elasticity value, or vice versa. Ratio polypropylene matrix added has influenced the modulus elasticity as well, the higher ratio has contributed to the higher modulus elasticity. The consideration of filler composition and polypropylene ratio inside the bio composite will be depending on the application of bio composite, where some application will require hard bio composite and some other will require flexible bio composite.

\subsection{Water Absorption Property}

Water absorption is the physical properties which reflect the ability of the bio composite to absorb water after 24 hours. The water absorption of bio composite can be seen in Figure 4.

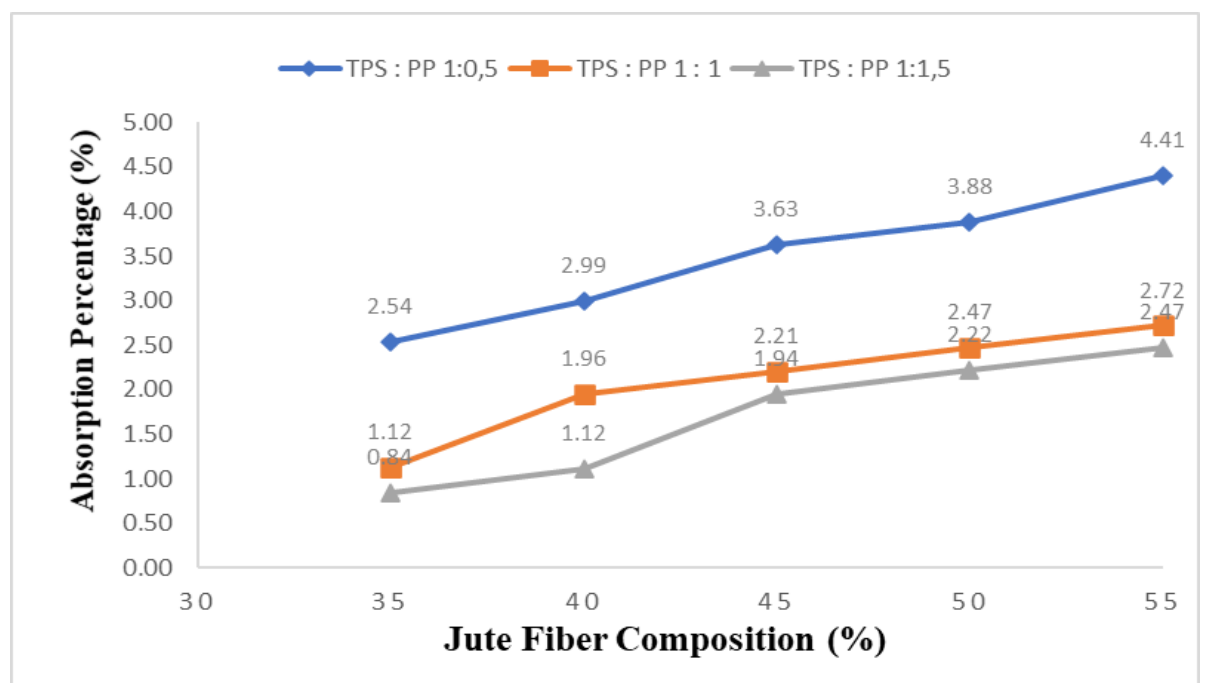

Fig 4. Water Absorption Percentage of Bio Composite with different Composition of Jute Fiber Filler on different ratio of propylene composition

From Figure 4, it can be seen that the values of bio composite water absorption bio composite influenced by the addition of filler. Higher filler incorporating into the bio composite gave higher ability to absorb water. Bio composite with jute fiber filler of $55 \%$ has water absorption of $4.41 \%$, while $35 \%$ filler has water absorption of $2.72 \%$. When analysis the ratio of Polypropylene in the bio composite, it can be seen that higher ratio of polypropylene inside the bio composite has made the ability of bio composite to absorb the water become lower, while lower polypropylene ratio has influenced to the higher water absorption capacity. Sago starch is hydrophilic, easy to absorb water, hence addition of polypropylene has limited the ability of bio composite to absorb water. High water absorbency will reduce the performance of bio composite, so the lower the ability of the water absorption, the better the quality of bio composite product and the broader the application can be.

\section{Conclusion}

More filler added into the bio composite has led into the decreasing the tensile strength. The decrease of tensile strength is caused by the interaction between the matrix and filler is weakened, so that the force exerted on the matrix does not transfers well on filler which finally make the composite to be less robust against load. Polypropylene is used to improve composite strength and give plastic behaviour as the thermoplastic sago starch has limited strength if used as single matrix without additional synthetic polymer. Same phenomena applied to percent elongation, where higher jute filler and polypropylene ratio gave lower percent elongation. Percent elongation should be 
designed according to the needs and application, hence it should become the consideration when characterize the quality of the bio composite whether the products is desire to be flexible or less flexible. Addition of fiber filler into the bio composite has influenced the modulus elasticity, higher filler volume incorporating into the bio composite has lowering the modulus elasticity value, or vice versa. Ratio polypropylene matrix added has influenced the modulus elasticity as well, the higher ratio has contributed to the higher modulus elasticity. In term of water absorbency, sago starch is hydrophilic, easy to absorb water, hence addition of polypropylene has limited the ability of bio composite to absorb water. High water absorbency will reduce the performance of bio composite, so the lower the ability of the water absorption, the better the quality of bio composite product and the broader the application can be.

\section{Acknowledgement}

This research was funded by Directorate of Research and Community Service (DRPM) Ministry of Education and Culture of the Republic of Indonesia in 2021. This research was done in 6 months period, with the assistance of two laboratory assistants at Chemical Engineering Laboratory, Faculty of Engineering, Universitas Malikussaleh.

\section{References}

[1] D. R. Paul and L. M. Robeson, "Polymer nanotechnology: Nanocomposites," Polymer (Guildf)., vol. 49, no. 15, pp. 3187-3204, 2008, doi: 10.1016/j.polymer.2008.04.017.

[2] N. Sylvia, Y. Yunardi, H. Husni, and A. Muslim, "Simulation of CO2 Gas Adsorption Process Flow at Cyclone Gas Outlet in Palm Oil Mills Using Computation Fluid Dynamic Simulation," Int. J. Eng. Sci. Inf. Technol., vol. 1, no. 3, 2021, doi: 10.52088/ijesty.v1i3.112.

[3] R. Dewi, N. Sylvia, and M. Riza, "The Effect of Rice Husk and Saw Dusk Filler on Mechanical Property of Bio Composite from Sago Starch,” Int. J. Eng. Sci. Inf. Technol., vol. 1, no. 3, 2021, doi: 10.52088/ijesty.vli3.113.

[4] S. Silviana and A. Subagio, "Biocomposite characterization of bagasse starch derived from cassava reinforced by acetylated bamboo cellulose and plasticized by epoxidized waste cooking oil," Rasayan J. Chem., vol. 12, no. 3, pp. 1470-1477, 2019, doi: 10.31788/RJC.2019.1235240.

[5] S. Arif, "Alternatif Penggunaan Plastik Polypropylene Pada Campuran Aspal," J. CIVILA, vol. 3, no. 1, p. 140, 2018, doi: 10.30736/cvl.v3i1.221.

[6] T. Imankulov, B. Daribayev, and S. Mukhambetzhanov, "Comparative analysis of parallel algorithms for solving oil recovery problem using cuda and opencl," Int. J. Nonlinear Anal. Appl., vol. 12, no. 1, 2021, doi: 10.22075/IJNAA.2021.4809.

[7] S. Permana, M. Andriani, and D. Dewiyana, "Production Capacity Requirements Planning Using The Capacity Method Requirement Planning," Int. J. Eng. Sci. Inf. Technol., vol. 1, no. 4, 2021, doi: 10.52088/ijesty.v1i4.165.

[8] R. Sudi, "The Study of Starch Seeds Durian (Durio zibethinus) Effect as the Filler Material on Tensile Strength and Biodegradation of Polymers Polystyrene (PS),” J. Aceh Phys. Soc., vol. 2, no. 1, pp. 7-8, 2013.

[9] R. Punyamurthy, D. Sampathkumar, R. P. G. Ranganagowda, B. Bennehalli, and C. V. Srinivasa, "Mechanical properties of abaca fiber reinforced polypropylene composites: Effect of chemical treatment by benzenediazonium chloride," J. King Saud Univ. - Eng. Sci., vol. 29, no. 3, pp. 289-294, 2017, doi: 10.1016/j.jksues.2015.10.004.

[10] Y. Yurike, Y. Yonariza, and R. Febriamansyah, "Patterns of Forest Encroachment Behavior Based on Characteristics of Immigrants and Local Communities," Int. J. Eng. Sci. Inf. Technol., vol. 1, no. 4, 2021, doi: 10.52088/ijesty.v1i4.170.

[11] S. Srithongkham, L. Vivitchanont, and C. Krongtaew, "Starch/Cellulose Biocomposites Prepared by High-Shear Homogenization/Compression Molding," J. Mater. Sci. Eng. B, vol. 2, no. 4, pp. 213-222, 2012.

[12] M. Mahfut, "Identification and Efforts to Control Infection Odontoglossum ringspot virus (ORSV) on Orchid," Int. J. Eng. Sci. Inf. Technol., vol. 1, no. 1, 2021, doi: 10.52088/ijesty.v1i1.38.

[13] V. Wineka Nirmala, D. Harjadi, and R. Awaluddin, "Sales Forecasting by Using Exponential Smoothing Method and Trend Method to Optimize Product Sales in PT. Zamrud Bumi Indonesia During the Covid-19 Pandemic," Int. J. Eng. Sci. Inf. Technol., vol. 1, no. 4, 2021, doi: 10.52088/ijesty.v1i4.169.

[14] R. Dewi, H. Agusnar, B. Wirjosentono, and M. Riza, "Synthesis of modified thermoplastic starch (TPS) using in-situ technique," Adv. Environ. Biol., vol. 8, no. 18, pp. 26-33, 2014.

[15] R. Dewi, Nasrun, Zulnazi, M. Riza, and H. Agusnar, "Improved mechanical and thermal properties of modified thermoplastic starch (TPS) from sago by using Chitosan,” Pertanika J. Sci. Technol., vol. 27, no. 3, pp. 1441-1450, 2019.

[16] L. Opirina, A. Azwanda, and R. Febrianto, "Analysis of The Mechanical Properties of Concrete Based on Fly Ash and Palm Oil Clinkers," Int. J. Eng. Sci. Inf. Technol., vol. 1, no. 4, 2021, doi: 10.52088/ijesty.v1i4.148.

[17] B. Juanda Surbakti, V. Mardina, and B. Al Fajar, "Effect of Sphagneticola Trilobata Extract on Histological Wistar Rat Kidney Induced by DMBA," Int. J. Eng. Sci. Inf. Technol., vol. 1, no. 3, 2021, doi: 10.52088/ijesty.v1i3.82.

[18] A. Balaji, B. Karthikeyan, and C. Sundar Raj, "Bagasse fiber - The future biocomposite material: A review," Int. J. ChemTech Res., vol. 7, no. 1, pp. 223-233, 2015.

[19] F. Xie, E. Pollet, P. J. Halley, and L. Avérous, Polysaccharides. 2021

[20] O. Faruk, A. K. Bledzki, H. P. Fink, and M. Sain, "Biocomposites reinforced with natural fibers: 2000-2010," Prog. Polym. Sci., vol. 37, no. 11, pp. 1552-1596, 2012, doi: 10.1016/j.progpolymsci.2012.04.003. 